\title{
Articles
}

\section{The Foresee Approach to Integrated ESL Instruction}

\section{Richard Kidd and Brenda Marquardson}

This article describes the Foresee Approach to integrating academic content, language, and learning strategy instruction in K-12 ESL or mainstream/partESL classrooms. An extension of Chamot and O'Malley's CALLA, the Foresee model was developed in Manitoba to assist teachers in implementing a CALLAbased style of integrated ESL instruction. Like CALLA, Foresee includes both theoretical and practical constituents, although these differ somewhat from their CALLA counterparts. The Foresee Theoretical Model guides the formulation of instructional objectives in the three target categories, especially academic language. The Foresee Application Process provides teachers with a practical scheme for designing effective integrated lessons and units. Included in this constituent is a set of systematic, straightforward, and adaptable lesson techniques (not part of CALLA) that teachers can use to plan the procedures sections of Foresee lessons. Five such techniques are described, one in detail and the others briefly, with emphasis on learning strategy instruction.

The practice of integrating the teaching of language and content (Mohan, 1986; Crandall, 1987; Cantoni-Harvey, 1987; Brinton, Snow, \& Wesche, 1989; Snow, Met, \& Genesee, 1989; Short, Crandall, \& Christian, 1989; Carrasquillo $\&$ Rodriguez, 1996) assumes an extra dimension in the work of Chamot and O'Malley $(1986,1987,1989,1994)$, who argue persuasively for the inclusion of learning strategies as an important third component of content-based ESL instruction. We support their view that fully integrated ESL teaching should incorporate all three of these elements, and we have devised for this purpose an instructional model called the Foresee Approach. This new model is a modification, or more accurately an extension, of the Cognitive Academic Language Learning Approach (CALLA) developed by Chamot and $\mathrm{O}^{\prime}$ Malley, and we gratefully acknowledge our debt to their inspiration and insights. The major innovations of our Foresee model lie mainly on the level of practical application, where we introduce a number of original ideas for teaching language and learning strategies through content material. These teaching procedures have been used successfully with ESL students at both the elementary and secondary levels, mainly in ESL classes, but also in 
mainstream subject-area classrooms containing a mixture of English L1 and ESL students.

The name Foresee derives from the homophone $4 \mathrm{C}$, which stands for Communication, Cognitive-Academic Language Development, and Content Instruction in the Classroom. A detailed explanation of the Foresee Approach can be found in Kidd and Marquardson $(1993,1994)$, two sourcebooks published by Manitoba Education and Training to assist both ESL and regular classroom teachers in implementing an integrated style of instruction. The purpose of this article is to introduce our model to a wider audience. We describe it as thoroughly as possible in the limited space available, placing special emphasis on the teaching of learning strategies. The discussion assumes some familiarity with CALLA, especially Chamot and O'Malley's five-stage lesson format (Chamot \& O'Malley, 1986, 1989) and their taxonomy of learning strategies (Chamot \& O'Malley, 1987; see Appendix).

The Foresee Approach consists of two distinct but related constituents or models. The first of these, the Foresee Theoretical Model, guides teachers in establishing appropriate lesson objectives, especially the learning strategies and specific language features that can be taught through the content material they select. The second constituent, the Foresee Application Process, provides a practical scheme for planning effective lessons and units. We begin by explaining the basic structure of these two complementary parts of our approach, and then expand on the application process by describing five specific lesson techniques-one in detail, the others briefly-that teachers can use to plan the procedures sections of Foresee lessons.

\section{Establishing Objectives: The Foresee Theoretical Model}

This constituent incorporates the three-component model of CALLA (Chamot \& O'Malley, 1986, 1987, 1989, 1994), but introduces an original diagrammatic representation in the form of the triangular configuration shown in Figure 1. The three large circles represent the content, language, and learning strategies components of integrated instruction. These major components are mutually supportive rather than separate and isolated, with the two-way arrows in the diagram indicating the interactions among them. First, content provides the vehicle through which academic language proficiency can be developed and various important learning strategies can be learned and practiced. The position of the content component at the apex of the triangle is quite fitting because Foresee, like CALLA, is a content-driven model (Chamot, O'Malley, \& Küpper, 1992). Conversely, the content itself is mastered more easily if students have acquired the linguistic tools (vocabulary, structures, language skills, etc.) needed for academic work, and if they employ good learning strategies. Language and learning strategies are thus appropriately situated at the base of the triangle, inasmuch as they combine to provide a solid foundation for the learning of subject matter. As for the 
interaction between the two base components, good learning strategies can assist students to acquire a second language (Rubin, 1975; Naiman, Frölich, Stern, \& Todesco, 1978; Oxford, 1990; O'Malley \& Chamot, 1990), while good language skills are important to the successful application of the learning strategies themselves (e.g., good listening skills are obviously essential to efficient notetaking, one of the cognitive strategies identified by Chamot \& O’Malley, 1987).

We now describe briefly the composition of the three major components of this model. As shown in Figure 1, each contains a similarly configured set of three subcomponents.

The Content Component. Success in the content areas depends on the acquisition of two different kinds of knowledge, declarative and procedural

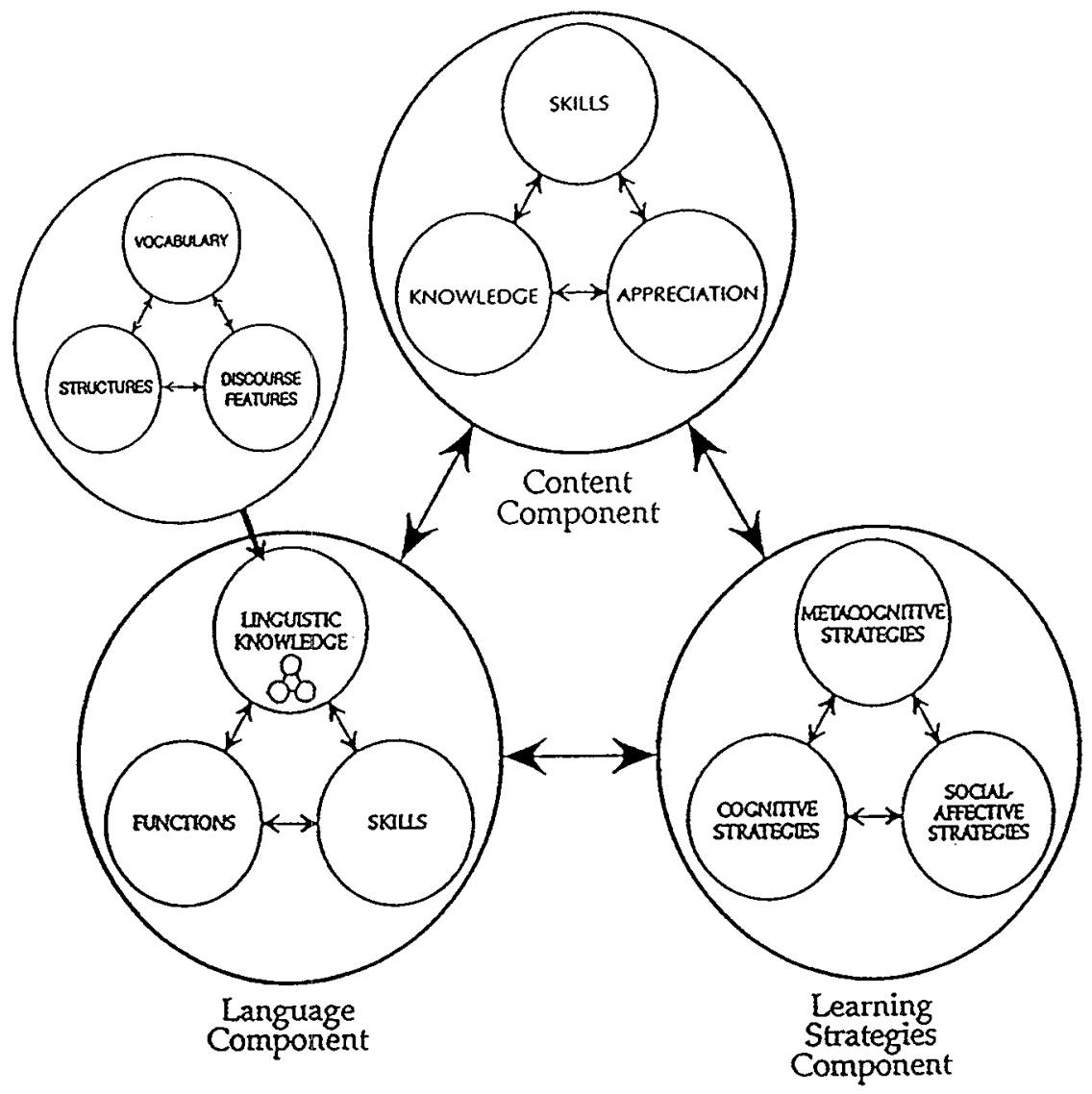

Figure 1. The Foresee Theoretical Model. 
(Anderson, 1985; Chamot \& O'Malley, 1987). Declarative knowledge, what students know about the subject matter, consists of facts (individual pieces of information) and the relations between them. Procedural knowledge, usually called skills, comprises what students know how to do in the various content areas. These may be subject-specific skills (e.g., calculating, performing science experiments) or more generic academic skills (e.g., problem solving). Linguistic knowledge and skills are obviously part and parcel of many of these content-area skills, but language-for the sake of pedagogical clarity and simplicity-is better situated in a separate component. Finally, a third goal of content instruction should be to instill an appreciation of academic subject matter and the importance of learning it. One of the most important aims of Foresee is to promote a positive attitude toward schooling. Our approach sets the students up for success, as we are fond of saying, and they usually respond quite positively to it.

The Language Component. Chamot and $\mathrm{O}^{\prime}$ Malley (1987) include four important "aspects of language" in their "language development component." These are (a) vocabulary, (b) academic language functions, (c) structures and discourse features (grouped together), and (d) language skills (listening, speaking, reading, and writing for academic purposes). We prefer to distinguish three separate subcategories here, rather than the four they suggest. In our model, vocabulary is grouped with grammatical structures (syntactic and morphological) and discourse features in a subcomponent called linguistic knowledge-what ESL students need to learn about language forms of these three types. The learning of such forms is obviously necessary for success in content-area work, but it is certainly not sufficient. Students must also acquire control over academic language functions (or ALFs for shorthow to use language forms to perform academic tasks such as defining, classifying, expressing cause and effect, explaining, describing, evaluating, etc.) and develop good academic language skills (listening, speaking, reading, and writing, the modes through which the various ALFs are accomplished). The three language subcomponents are represented by the smaller triangle in the language component in Figure 1. Note that the linguistic knowledge subcomponent contains its own triangle (inset): vocabulary, structures, and discourse features.

As mentioned above, the practical value of both the content and language components lies in their potential for generating lesson objectives. We admit that our content component is unlikely to be of much help to teachers who are experienced at selecting and teaching content material. On the other hand, we believe that most teachers can benefit from an organized scheme for establishing appropriate language objectives. One strength of our proposed language component is that it focuses attention on a variety of diverse but related linguistic subcategories. All teachers recognize the need to teach vocabulary and language skills to ESL students, but relatively few 
possess a linguistically grounded explicit understanding of structures, discourse features, and academic language functions. The Foresee language component aims to provide the linguistic guidance necessary for planning objectives in these categories. Obviously this component requires elaboration to be helpful, but an in-depth analysis of its various subcomponents is beyond the scope of this article (see Kidd \& Marquardson, 1993, 1994, for a fuller treatment). Here we simply observe that the language component provides a representational guide for teachers, a template that helps ensure that attention is paid to the teaching of a broad range of academic language features. Foresee lesson plans normally include language objectives in all the subcategories discussed above.

We should also mention at this point that we recognize the need for analytic as well as experiential instruction (Allen, 1988) in all aspects of academic language: grammatical structures, discourse features, functions, and so forth. By analytic instruction we mean explicit, focused attention to specific language features. In this respect Foresee differs slightly from CALLA, which emphasizes the development of language proficiency mainly through practice and experience. In the words of Chamot and O'Malley (1987), the purpose of the language development component of CALLA is to give students

sufficient practice in using language in academic contexts so that language comprehension and production become automatic and students develop the ability to communicate about academic subjects. (p. 234, emphasis added)

The Learning Strategies Component. Chamot and O'Malley (1989) have often emphasized that the instruction of learning strategies is a unique feature of CALLA. They describe these strategies as "conscious techniques that facilitate learning both language and content" (p. 116), drawing on extensive research evidence (O'Malley \& Chamot, 1990) to argue that students can dramatically improve their ability to understand and remember new information if they make a deliberate effort to learn and apply a variety of these learning strategies, ideally to the point of automaticity.

A large number of specific learning strategies have been identified in the literature. Oxford (1990), for example, names and describes no fewer than 62 distinct strategies that can be applied to the task of learning a second language. Chamot and O'Malley $(1986,1987)$ have narrowed the list to a manageable number, focusing on around 18 strategies that are particularly useful for learning both language and content in academic contexts. They group these various strategies into three categories, metacognitive, cognitive, and social-affective. As indicated in Figure 1, their scheme has been adopted, unchanged and intact, as the learning strategies component of the Foresee Theoretical Model. 
1. Metacognitive strategies are strategies relating to the planning, monitoring, or evaluating of one's own learning. They come into play when students think about how to approach or attack a learning task, or when they consciously assess how successfully a learning task is proceeding or has proceeded.

2. Cognitive strategies are strategies that can be applied directly to the tasks of understanding and learning. These strategies may be mental (e.g., forming mental images to aid memorization) or physical (e.g., notetaking, using resource materials).

3. Social-Affective strategies are strategies through which the learner either enlists the support or assistance of other people (e.g., peers, teachers) or establishes an emotional or attitudinal state of mind conducive to success.

Classroom instruction focusing on these strategies should not be regarded as a frill, a mere supplement to the teaching of more important material (i.e., content and language). The mastery of learning strategies constitutes a major pathway to empowerment, a means through which students can develop into autonomous and independent learners. Like Chamot and O'Malley, we strongly recommend that they be explicitly taught and consciously practiced through the vehicle of content-area work. At the same time, we believe that well-designed instruction often includes opportunities for students to make use of good learning strategies on an implicit level, without paying special attention to them. This experiential route to learning is a prominent feature of our approach, as we demonstrate below.

For the reader's convenience, a complete list of Chamot and O'Malley's (1987) learning strategies and their descriptions is included in the Appendix. This list is supplemented by additional comments and explanations intended to clarify how these learning strategies are often taught and/or used in Foresee instructional activities.

\section{The Foresee Application Process}

We turn now to the matter of classroom practice. How can teachers design good integrated lessons and units that successfully accomplish the assorted objectives outlined above? This crucial question has not, in our opinion, been adequately addressed in most current models of content-based ESL instruction, despite the fact that an integrated approach is not easy to implement successfully without a modicum of specific help and guidance. One familiar way of providing such assistance has been to equip teachers with prepared or packaged units written by experts. A good example is Chamot et al.'s (1992) series Building Bridges: Content and Learning Strategies for ESL, which is published in three levels (Book 1-high beginning; Book 2-low intermediate; Book 3-intermediate). This series provides secondary-level teachers with units-sets of carefully structured lesson plans or activities-that 
they can use directly for implementing CALLA in their classrooms. These units are built around interesting content topics and are specially designed for teaching learning strategies. Similar CALLA-based materials have been produced to assist the teaching of specific subject areas such as mathematics (Chamot \& O'Malley, 1988) and social studies (Chamot, 1987a, 1987b). Materials of this type often contain a wealth of interesting topics and good teaching ideas and can, therefore, be useful to classroom teachers even if they are not followed to the letter.

In developing the practical side of the Foresee Approach, we have chosen a different option for assisting teachers through the implementation phase. For one thing, class sets of materials are not easily affordable in these days of dwindling educational resources. Even more importantly, many teachers dislike having to follow packaged materials designed by someone else. They prefer instead to create their own lessons and units, partly for personal satisfaction but mainly because they know that tailor-made instruction has the best chance of meeting the particular needs and interests of their students. We recognize and respect this preference for individual creativity and have adopted it as a central element of the Foresee application process.

We also realize, however, that there are limits to creativity. As much as teachers may prefer to develop their own lessons and units, most do not aspire to be materials developers. That is, they do not make a practice of producing original books, stories, poems, songs, content-area texts, pictures, or other materials around which they can build exciting and motivating lessons. Rather, their creativity lies in their expertise at selecting, manipulating, and sometimes adapting appropriate published materials (textbooks, reference books, storybooks, ESL materials, or whatever) that can be used as the nuclei of effective instruction. Teaching has often been called an art, and at the elementary level, especially, an important facet of that art is skill at exploiting available materials for one's own pedagogic purposes. The Foresee Approach recognizes this common practice as an important aspect of the application process (see Figure 2).

Turning to specifics, the application of the Foresee Approach can be viewed as a dynamic interaction or synthesis of three separate elements. The component at the bottom left, labeled theory, is simply the Foresee Theoretical Model. As we have seen, this component generates appropriate lesson objectives in a range of categories. Because the establishment of worthwhile objectives is a crucial part of instructional planning, we regard our theoretical model as an indispensable part of the application process. In short, it helps teachers decide "what to teach."

Next comes the materials component, informal guidelines about "what to use" $^{\prime \prime}$ as the physical substance of Foresee instruction. As mentioned above, Foresee is independent of packaged materials or multilevel instructional series of any kind. Instead of relying on such materials, which are often 


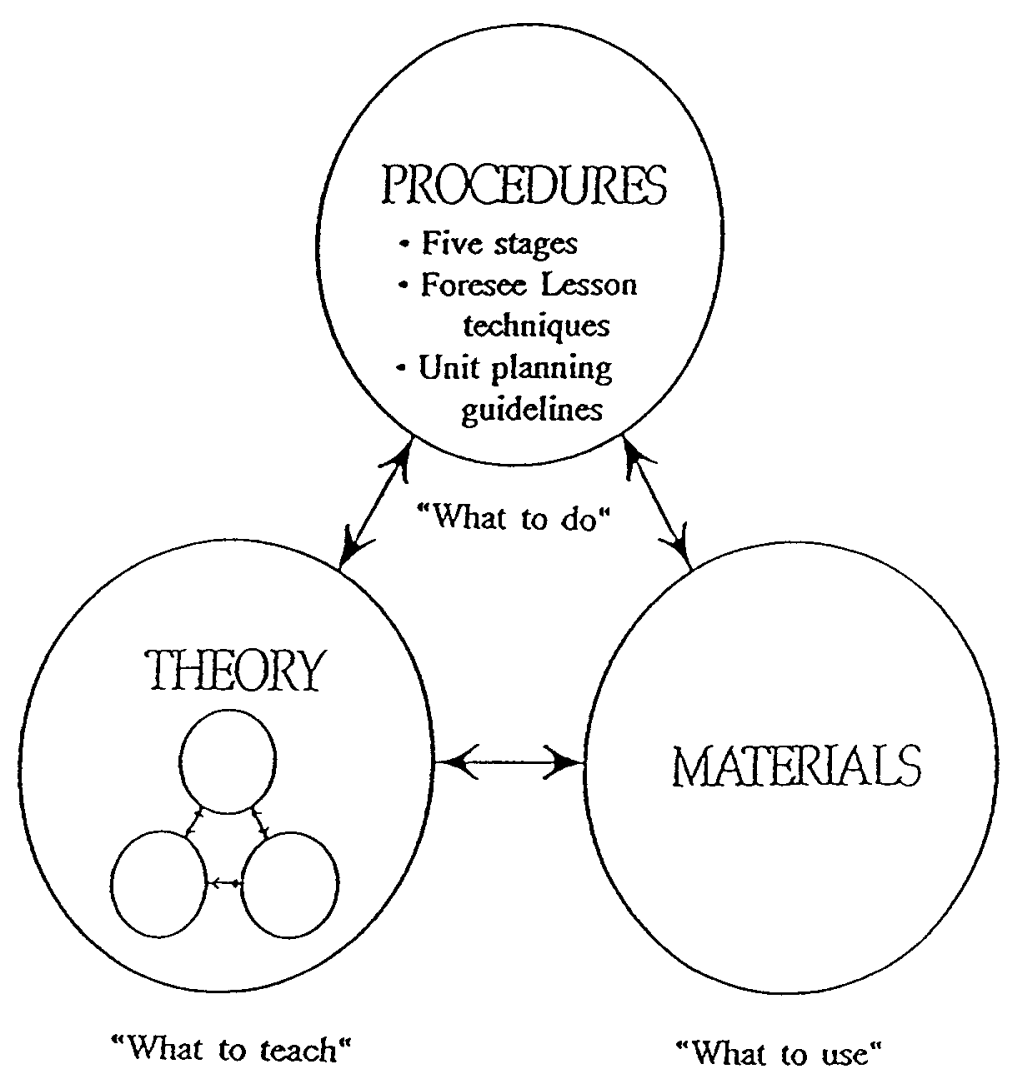

Figure 2. The Foresee Application Process.

expensive, our application process is structured to allow teachers to make systematic use of content-area materials they discover and select on their own. Although such materials may on occasion be produced by the teacher, they most often tend to be published resources of various types-expository articles, stories, poems, pictures or other visuals, and so forth-around which teachers can build individual lessons and even entire units. The best materials are those that are visually appealing (colorful, well illustrated, attractively laid out, etc.), interesting and motivating in content, and readily adaptable to the students' needs and interests. Some valuable sources of good materials for Foresee instruction are subject-area textbooks, ESL teaching manuals, children's storybooks, books of poems or songs, children's nonfiction books, reference books, newspapers, and magazines. 
So much, then, for the two base components of the Foresee application process. To summarize, the theory generates the objectives and the materials provide the substantive base for Foresee instruction. The third indispensable ingredient of application is a set of guidelines for planning the actual instructional activities that take place in the classroom. These are contained in the procedures component, which sits at the apex of the application triangle in Figure 2 because it represents the actual how of Foresee instruction, helping teachers plan "what to do" in their classrooms. As might be expected, the procedures we have developed in Foresee lend themselves in a straightforward way to the accomplishment of a variety of objectives (including the teaching of learning strategies) and to the manipulation and use of selected materials.

This component contains guidelines to two related but distinct levels of lesson design: lesson organization and lesson techniques. As regards the first level, Foresee lessons are usually organized to follow the five-stage instructional format suggested by Chamot and O'Malley (1986, 1989). The five stages or phases of a typical CALLA lesson are preparation, presentation, practice, evaluation, and follow-up (or expansion). We have found that this scheme constitutes an excellent format for including target objectives of all three types - content, language, and learning strategies - in any Foresee lesson. Our model differs somewhat from CALLA, however, with respect to the particular activities that commonly occur in some of the stages, especially the preparation and follow-up. In the Foresee preparation phase, the teacher usually prepares the students for the lesson by making methodical use of selected visual supports (pictures, diagrams, realia, etc.) to trigger the recall of prior knowledge and experiences related to the topic, to build further conceptual knowledge, and to introduce important new vocabulary. In the follow-up stage, which CALLA employs mainly to consolidate or extend the new knowledge and skills that have been acquired, Foresee tends to focus on language development activities of various types, especially writing.

Although the five-stage format is useful as a general guide, we are convinced that it lacks the detail that teachers need to plan effective lessons quickly and easily. Foresee therefore supplements this scheme with a repertoire of specific lesson techniques, step-by-step routines for exploiting materials and implementing activities. These techniques, the most innovative feature of our approach, constitute the second level of our procedures component. Teachers can simply plug the content into these formalized procedures in order to plan effective integrated lessons. As we demonstrate in the next section, they are:

- systematic - they contain a sequence of detailed, specific steps that

teachers can follow in planning their lessons; 
- straightforward-although some of the techniques are slightly complicated in some places, they are certainly not difficult to understand, and with a little practice they are easy to implement;

- flexible-they can be modified to suit the topic, the students' needs, the teacher's preferences, and so forth;

- adaptable or generalizable- they can be applied to the teaching of a wide variety of topics in different subject areas.

As we see, these lesson techniques offer a further advantage as well: they are designed so that learning strategy practice is built into many of their individual steps, relieving teachers of the burden of planning how to incorporate strategy instruction into their lessons.

As noted, these techniques pertain specifically to lesson design. Before turning to their detailed description in the next section, let us briefly consider another important aspect of the Foresee Application Process, unit planning, which is also listed as part of the procedures component.

Foresee unit development generally follows a theme-based approach (Gamberg, Kwak, Hutchings, \& Altheim, 1988; Brinton et al., 1989; Enright \& McCloskey, 1988). In planning a Foresee unit, the teacher usually begins by choosing a theme or topic based on some attractive, motivating materials that are available. We certainly make no claims to originality in this regard, and we recognize that most elementary teachers use theme-based instruction a good deal of the time. Nonetheless, the way we organize theme-based units to fulfil the aims of Foresee instruction, especially the integration of content instruction with the teaching of language and learning strategies, is somewhat different from previous applications along these lines.

Foresee units also tend to be highly integrated with respect to the different academic content areas. Many different subject areas can usually be incorporated into, and taught via, any unit, particularly at the elementary level. For example, our grades 4-6 Foresee unit on the solar system (Kidd \& Marquardson, 1993) contains instruction in the areas of science, mathematics, social studies, and language arts. Although these subjects are taught in separate lessons, all relate to the central theme somehow.

As a final comment on unit planning, it is worth noting that Foresee units tend to be built around the various lesson techniques. These techniques generally form the backbone of a unit, so to speak; the teacher makes use of as many of them as possible, supplementing them with original lesson ideas as required to fill out the unit. The various lesson techniques are, therefore, crucial to unit planning as well as to lesson planning.

\section{The Foresee Lesson Techniques}

The five lesson techniques we describe in this section all meet four important criteria mentioned above: they are systematic, straightforward, flexible (modifiable), and adaptable (generalizable) to a wide variety of content-area 
topics. As mentioned, these techniques function as prefabricated guidelines to the planning of the "procedures" section of lessons. In our experience, such planning is usually the main stumbling block to the successful implementation of integrated ESL instruction. By using these special lesson techniques, however, teachers will find it relatively simple to design lessons that accomplish the threefold objective of promoting students' learning of content, language, and learning strategies.

The first technique, the TQT, is described in considerable detail. Regrettably, limitations of space prohibit anything more than capsule summaries of the other four techniques, but these should suffice to convey the flavor of Foresee instruction.

\section{The Text Questioning Technique}

The Text Questioning Technique, or TQT for short, is particularly valuable for introducing a new topic. However, it can be used at any point during a unit when good materials are available and the topic is suitable.

Good materials are critical to the application of the TQT. Two things are required: an appropriate reading passage on the target topic (the text), and accompanying visuals. The text is usually selected from a class textbook or adapted from another source (e.g., a reference book, newspaper, or magazine) and distributed to every student. It should be of moderate length and geared to the reading level of the students. Ideally, it should contain a reasonable sampling of linguistic features (vocabulary, structures, discourse features, and academic language functions or ALFs) that can be established as language objectives for the lesson. Finally, it should be accompanied by a title and preferably, but not necessarily, by headings and even subheadings.

The accompanying visual should, as far as possible, present a graphic or pictorial representation of most of the information contained in the text. The teacher can thus use it as a vehicle to drive context-embedded discussion and brainstorming aimed both at evoking prior knowledge and at eliciting, developing, or supplying concepts and vocabulary that are important for understanding the text itself.

Preparation stage (brainstorming-speaking and listening). This stage is designed to provide an introduction and orientation to the lesson topic. The text itself is not read during this phase. Rather, the teacher prepares the students for the eventual reading task by orchestrating a brainstorming session based on an examination of the text title, other typographical information such as subheadings and captions, and all visual supports (pictures, diagrams, etc.). This process activates the students' relevant prior knowledge about the topic and brings to the fore some of the important vocabulary in the text. It also gives the students an opportunity to make predictions about the contents of the text. 
The teacher usually begins this phase by asking the students to turn to the reading passage (in a book or on a handout) and look at the title and accompanying visuals for a short time, one or two minutes at most. Without reading the text itself, they try to guess or predict (to themselves) what the passage is about and some of the details it may contain. When time is up, they are asked to close their books (or turn over their handouts) and write down their predictions in a few words. (Spelling, sentence structure, and so forth are not important at this time.) The teacher then listens to each student's predictions, writing on the chalkboard all the key words that are volunteered. If certain key words are missed, the teacher refers the students to the visuals again and elicits the unmentioned items through pointed questioning or, if necessary, tells the students the words they do not know. This activity should be thoroughly and carefully planned, not simply performed off the cuff. A comprehensive list of good brainstorming questions is indispensable in helping the teacher to extract the desired ideas and vocabulary from the visuals. Without such a list the visuals may not be utilized effectively and the whole lesson may fail.

At the end of this process, the students will have before them all the vocabulary necessary for understanding the reading passage; furthermore, they will have a good idea of what the whole passage is about before they read it. Obviously this entire activity gives students excellent practice in applying Chamot and O'Malley's learning strategy of Advance organization (previewing a text, along with other accompanying visuals and other clues such as titles and headings, to get the main ideas; see the Appendix). They also gain experience with the strategies of Inferencing (guessing the content of the text from available clues) and Imagery (using visual images to understand new information).

Presentation (listening). In this stage, the students are exposed to the main contents of the text through a notetaking activity that helps develop their listening skills. First, they close their books (or turn over their handouts). Then the teacher shows them a numbered list of questions about the text (the question list), either on the overhead or on the chalkboard (previously concealed). The students read all the questions silently, and then the teacher reads them aloud one by one, explaining any words the students do not understand and underlining key words they will soon be listening for. Next, the students write the question numbers (not the questions) down the left margin of their notebooks in preparation for notetaking. Then the teacher reads the entire passage aloud, fairly slowly, and the students listen carefully for information that will help them answer the questions, which remain visible on the board (or overhead). Usually the teacher facilitates the listening task by deliberately accentuating helpful discourse signals and the key words that have been underlined in the questions. As the students hear the answers, they write them in short form (one or two words, or abbreviations 
or numbers) beside the corresponding numbers on their papers. Because few students generally succeed in answering all the questions from the first reading, the teacher dictates the passage again once or twice, more rapidly this time, to allow them the opportunity to check their answers. This entire activity gives the technique its name: the Text Questioning Technique.

The most obvious learning strategy practiced in this phase is Notetaking (writing down key words and concepts in abbreviated form). Other strategies employed are Organizational planning (when listing question numbers in preparation for notetaking), Selective attention (when listening for key words that provide clues to the required answers), Self-monitoring (when checking the accuracy of answers, especially on the second or third readings), and Auditory representation (retaining strings of words in short-term memory while notetaking).

Practice (reading, speaking, and writing). The students now open their books (or turn over their handouts) and read the text silently. Their comprehension is usually high, as they have been thoroughly prepared for the task. They then work in pairs, comparing their note-style answers and checking them against the text itself. At this point they should pay careful attention to the form of their short responses, ensuring that all abbreviations are expanded to full words or phrases and that all words are spelled correctly. A set time limit (e.g., 10 minutes) is usually allotted to this task. The teacher circulates around the classroom during this phase, providing assistance when requested. By focusing attention on the checking and correcting of their work, the students gain experience with the metacognitive strategy of Self-evaluation. They also have a chance to practice the social-affective strategies of Cooperation and Questioning for clarification.

Evaluation (speaking). Books are closed or handouts turned face-down (or collected by the teacher, as they are no longer needed). In this phase, the teacher goes through the questions on the board or overhead one by one, asking individual students to contribute the short answers they have written and expanded. As these responses are given, the teacher writes them after the corresponding questions, usually in a different color (chalk or overhead pen). By correcting their own work at this point, the students gain further practice in Self-evaluation.

Follow-up (writing). This is mainly a language development phase in the TQT. Books remain closed or handouts face-down (if they have not already been collected). The teacher demonstrates how to write proper full-sentence answers to some of the questions on the question list, emphasizing that this is usually a matter of rearranging some of the words in the questions and combining them with the correct answers. Words and phrases can be underlined and arrows drawn to show how this is done, with the use of different colors adding effect to the demonstration. The teacher may call the students' attention to some of the language features that have been targeted for in- 
struction in the lesson, if these features appear in the answers that the students will write. Important structures, discourse features, and/or language functions can be explained to the students or illustrated through examples, so that the students will be able to handle these when they encounter them in their answer-writing.

After the preliminary demonstrations and explanations, the students finish the activity individually by writing the answers in complete sentences. By doing this, they gain valuable experience with a variety of formal aspects of academic language, including grammatical structures, vocabulary, spelling, punctuation, capitalization, and discourse markers. They may also have a chance to accomplish ALFs such as defining, comparing, contrasting, and expressing cause and effect. If the questions are phrased and organized appropriately, this activity can also provide multiple opportunities for practice in sentence combining.

After the students complete their answers, they again work in pairs and help their partners by editing their work. When the members of each pair think their answers are correct, they present their papers to the teacher and, if time allows, read their answers aloud.

Once again, students get the chance to practice the learning strategies of Self-evaluation and Cooperation. As they wrestle with problems of linguistic form and expand their short answers into full sentences, they also practice Deduction/induction and Elaboration.

We describe the TQT in considerable detail because it illustrates all the qualities of a good Foresee technique. It is adaptable, that is, easily applied to the teaching of numerous topics in different subject areas, as all that is required for its use are a suitable text and visuals. It is also flexible, as it can be modified at a number of points to suit the wishes of the teacher; for example, in the presentation phase the students could answer the listed questions by reading the text rather than listening to it. It is systematic and, despite being quite detailed in places, straightforward and easy to implement. Finally, as promised above, it incorporates learning strategy practice as a built-in feature, obviating the need for special planning on the part of the teacher.

The other four lesson techniques all share these same qualities. Like the TQT, they consist of sequences of well-specified, easy-to-follow steps organized into the five-stage format. We describe these other techniques more briefly, focusing mainly on the major activities of each procedure and the learning strategies that can be taught or practiced via their implementation.

\section{The Research Technique}

The Research Technique gives students the chance to perform individual research on particular aspects of the main topic of the unit. It works best when the subtopics are all of the same type; in a unit on the solar system, for 
example, each student could investigate a planet of his or her choice. Because all the subtopics are semantically similar, the teacher can prepare a common research outline that guides students on what to look for (e.g., diameter of their planet, distance from the sun, etc.) in library books and other resources, perhaps even on the Internet. The experience culminates in writing a research report based on the notes compiled. This technique gives students experience in using the metacognitive strategies of Organizational planning (using a structured guide when accumulating information about a topic) and Selective attention (looking for key words in the resource materials to help them locate the required information). They also practice the cognitive strategies of Resourcing (using reference materials to gather information), Notetaking (from written texts), Imagery (using pictures in their reference books as sources of information), Elaboration (extending their knowledge of one particular content subtopic, and expanding their written notes into good research reports), Summarizing, and Deduction/induction (using knowledge about language to produce well-written reports). Extensive use of Cooperation also occurs. Note that because these strategies can all be conveniently illustrated through reference to their specific application during the lesson activity, they are easy to teach on an explicit level. The same holds true for the other techniques described below.

\section{The Presentations Technique.}

The main activity of the Presentations Technique is the class presentation of the research reports completed at the end of the Research Technique lesson. Each student makes a rehearsed oral presentation on his or her research findings, while the other students are required to take notes. To facilitate this receptive task, the teacher equips each student with a summary sheet, a notetaking guide containing the same informational categories in the same order as on the research outline.

Numerous learning strategies can be practiced or explicitly taught in presentations lessons, which usually extend over a number of class periods. These include the metacognitive strategies of Organizational planning, Selective attention, Self-monitoring, and Self-evaluation, the cognitive strategies of Notetaking, Summarizing, Grouping, Elaboration, Auditory representation, and Transfer, and the social-affective strategies of Cooperation, Questioning for clarification, and Self-talk.

\section{The Dictated Instructions Technique (DIT)}

The Dictated Instructions technique, an elaboration of a lesson idea in Chamot and O'Malley (1986), centers around a novel procedure for instructing students about the steps of any hands-on activity such as a science experiment. Instead of distributing a handout or having students copy the instructions from the chalkboard or overhead, the teacher dictates the neces- 
sary steps to the students. They copy these onto a supplied instructions sheet, which lists all the necessary instructions but in partial form only-it contains blank spaces in place of many of the important content words (especially imperative verbs) and sometimes function words as well (e.g., prepositions). After the dictation, the students work in small groups to pool their information and compile as full a set of instructions as possible, with the teacher giving assistance as needed. The students then perform the activity by following the completed instructions list. Finally, they write a report describing what they have done, transforming the instructions from the imperative form to past tense (e.g., I inserted the tube ...) or to past passive (e.g., The tube was inserted ...).

Of the many learning strategies that can be practiced or taught in DIT lessons, some of the most prominent are Selective attention (listening for specific discourse markers and other cues during the dictation), Notetaking, Questioning for clarification, and Cooperation.

\section{The T-List Procedure}

Our final technique is also based on a suggestion by Chamot and O'Malley (1986). The main activity of this procedure is the dictation of a text about a selected topic. During dictation, the students take notes on a T-list, a page with a vertical line down the middle, usually with certain information already on it (cue words and phrases, with blanks to be filled in). On the left side of the list the students note the main ideas of the passage. On the right side, they write supporting information (details, examples, and so on) beside the corresponding main ideas. After the dictation, the students work together to pool information and compile as accurate a list of notes as possible. Then the teacher enlists their help in filling in a transparency copy of the T-list, which the students use to correct their own lists. Subsequently, using an overhead marker of a different color, the teacher demonstrates how to add necessary function words (articles, prepositions, conjunctions, etc.) and punctuation to expand some of the notes on the T-list (usually the first section) into well-formed sentences. The students complete the writing task themselves, finishing with their own multiparagraph versions of the original text.

Again, the metacognitive strategy of Selective attention is prominent in this technique, as the students must attend to discourse markers and other verbal cues to fill out their T-lists successfully during the dictation. Other noteworthy strategies utilized in T-list lessons include Notetaking, Grouping, Elaboration, Self-evaluation, Cooperation, and Deduction/induction.

To conclude this brief overview of the Foresee lesson techniques, we wish to emphasize that the five procedures above form a repertoire that is still far from being fully stocked. We are continually working to expand the array of general lesson procedures suitable to the kind of integrated, CALLA-based 
ESL instruction we advocate, and we welcome any suggestions from ESL or mainstream teachers who might devise original techniques for this purpose. We are convinced that although theory and model-building may be the province of others, the development of effective techniques is a task best performed by classroom teachers themselves, as they have the ideal opportunity to experiment from day to day with new ways of utilizing attractive and motivating materials to teach content, language, and learning strategies to the ESL students in their charge.

On a final note, we wish to avoid leaving the impression that these formulaic lesson techniques are the be-all and end-all of Foresee instruction. Our approach has sometimes been criticized as being too rigid, too dependent on the application of a handful of prefabricated techniques that allow little opportunity for creativity or innovation in lesson design. As we observe above, however, the various lesson techniques are certainly flexible enough to be modified at the teacher's discretion-they are not carved in stone. More to the point, these techniques are not actually crucial to Foresee application at all. They serve as a useful starting point, a springboard for implementing the particular style of integrated ESL instruction that we advocate. With a little experience in applying the techniques, many teachers quickly develop a deeper understanding or awareness of the essence of our approach, the totality of principles underlying Foresee methodology in general. We call this the "spirit of Foresee" (Kidd \& Marquardson, 1997). Once teachers catch this spirit, they become empowered to transcend our small repertoire of formalized techniques and create their own original lessons as needed. In brief, such lessons can be characterized as being

1. built around interesting and comprehensible materials, both visual (pictorial) and textual;

2. divided into five discrete stages, each stage having the clear purposes exemplified by our standardized techniques;

3. carefully planned to include the intentional instruction of academic language and learning strategies, both explicit (analytical) and implicit (experiential); and

4. structured to lead students patiently and step-by-step through activities involving the fusion of language and content.

For other noteworthy features of the Foresee spirit, see Kidd and Marquardson (1997).

\section{Conclusion}

The recent trend toward the integration of language and content in ESL teaching has certainly been beneficial. We would argue, however, that true integration demands the inclusion of appropriate learning strategies as a third target of instruction, because only by mastering effective strategies for acquiring academic language and content can ESL students develop into 
empowered and autonomous learners. On these grounds, the seminal model incorporating this tripartite focus, Chamot and O'Malley's CALLA, obviously represents a major contribution to modern content-based ESL teaching. We find it disappointing, therefore, that the type of integrated instruction pioneered by Chamot and O'Malley has not become more widely practiced to date. Most mainstream teachers remain unaware of CALLA, and although the majority of ESL teachers are probably familiar with it to some degree, relatively few as yet, at least in Manitoba, have succeeded in implementing it effectively. Perhaps the main reason for this is that the CALLA application component lacks a set of generalizable, easy-to-use lesson procedures. Our purpose in developing the Foresee Approach has been to assist individual teachers in our province on a practical level, in their own classrooms, by providing them with a systematic and straightforward way of integrating the teaching of content, language, and learning strategies. We hope that the brief sketch of our model in this article will be of interest to teachers across Canada, and perhaps encourage them to experiment with an integrated, CALLA-based style of instruction that we have found so effective.

\section{The Authors}

Richard Kidd is an associate professor in the Faculty of Education, University of Manitoba, Winnipeg, Manitoba R3T 2N2 (Tel. 204-474-9045; FAX 204-474-7550). His research and scholarly interests include TESL/TEFL methodology, the teaching of ESL grammar, and the integration of language and content in ESL instruction.

Brenda Marquardson is an ESL support teacher at Tyndall Park Community School, $2221 \mathrm{King}$ Edward St., Winnipeg, Manitoba R2R 1M5 (Tel. 204-633-0065). She has been developing and applying Foresee methodology in her ESL classroom since first discovering CALLA in 1989. During the past few years she has delivered a number of teacher inservices on the Foresee Approach both nationally and internationally, traveling as far afield as London, England and Seoul, Korea.

\section{References}

Allen, J.P.B. (1988). The development of instructional models in second language education. Annual Review of Applied Linguistics, 9, 179-192.

Anderson, J.R. (1985). Cognitive psychology and its implications (2nd ed.). New York: Freeman. Brinton, D.M., Snow, M.A., \& Wesche, M.B. (1989). Content-based second language instruction. New York: Newbury House.

Cantoni-Harvey, G. (1987). Content-area language instruction. Reading, MA: Addison-Wesley.

Carrasquillo, A.L., \& Rodriguez, V. (1996). Language minority students in the mainstream classroom. Clevedon, UK: Multilingual Matters.

Chamot, A.U. (1987a). Language development through content: America: The early years. Reading, MA: Addison-Wesley.

Chamot, A.U. (1987b). Language development through content: America: After independence. Reading, MA: Addison-Wesley.

Chamot, A.U., \& O'Malley, J.M. (1986). A cognitive academic language learning approach: An ESL content-based curriculum. Wheaton, MD: National Clearinghouse for Bilingual Education.

Chamot, A.U., \& O'Malley, J.M. (1987). The cognitive academic language learning approach: A bridge to the mainstream. TESOL Quarterly, 21, 227-249. 
Chamot, A.U., \& O'Malley, J.M. (1988). Language development through content: Mathematics book $A$. Reading, MA: Addison-Wesley.

Chamot, A.U., \& O'Malley, J.M. (1989). The cognitive academic language learning approach. In P. Rigg \& V.G. Allen (Eds.), When they don't all speak English: Integrating the ESL student into the regular classroom (pp. 108-125). Urbana, IL: National Council of Teachers of English.

Chamot, A.U., \& O'Malley, J.M. (1994). The CALLA handbook. Reading, MA: Addison- Wesley.

Chamot, A.U., O'Malley, J.M., \& Küpper, L. (1992). Building bridges: Content and learning strategies for ESL. Student Books 1, 2, \& 3. Boston, MA: Heinle \& Heinle.

Crandall, J. (Ed.). (1987). ESL through content-area instruction: Mathematics, science, social studies. Englewood Cliffs, NJ: Prentice Hall Regents.

Enright, D.S., \& McCloskey, M.L. (1988). Integrating English. Reading, MA: Addison-Wesley.

Gamberg, R., Kwak, W., Hutchings, M., \& Altheim, J. (1988). Learning and loving it: Theme studies in the classroom. Portsmouth, NH: Heinemann.

Kidd, R., \& Marquardson, B. (1993). Sourcebook for integrating ESL and content instruction using the Foresee Approach. Winnipeg, MB: Manitoba Education and Training.

Kidd, R., \& Marquardson, B. (1994). Secondary sourcebook for integrating ESL and content instruction using the Foresee Approach. Winnipeg, MB: Manitoba Education and Training.

Kidd, R., \& Marquardson, B. (1997). The spirit of Foresee. TESL Manitoba Journal, 12(4), 3-5.

Mohan, B.A. (1986). Language and content. Reading, MA: Addison-Wesley.

Naiman, N., Frölich, M., Stern, H.H., \& Todesco, A. (1978). The good language learner. Toronto: OISE.

O'Malley, J.M., \& Chamot, A.U. (1990). Learning strategies in second language acquisition. Cambridge: Cambridge University Press.

Oxford, R. (1990). Language learning strategies: What every teacher should know. New York: Newbury House.

Rubin, J. (1975). What the "good language learner" can teach us. TESOL Quarterly, 9, 41-51.

Short, D.J., Crandall, J.A., \& Christian, D. (1989). How to integrate language and content instruction: A training manual. Los Angeles, CA: Center for Language Education and Research, UCLA. Eric Document Reproduction Service No. ED305824.

Snow, M.A., Met, M., \& Genesee, F. (1989). A conceptual framework for the integration of language and content in second/foreign language instruction. TESOL Quarterly, 23, 201-217.

\section{Appendix: List of Learning Strategies}

Note: Column 2 contains Chamot and O'Malley's (1987) descriptions of the learning strategies, word for word; column 3 gives explanations or comments relating to the frequent application of the strategies in instruction using the Foresee Approach.

\section{Metacognitive Strategies}

Strategies relating to the planning, monitoring, or evaluating of one's own learning

$\begin{array}{ll}\text { Advance } & \text { Previewing the main ideas and } \\ \text { organization } & \begin{array}{l}\text { concepts of the material to be } \\ \text { learned, often by skimming for the } \\ \text { organizing principle }\end{array}\end{array}$

Organizational Planning the parts, sequence, planning main ideas, or language functions A receptive strategy-looking at headings, subheadings, accompanying pictures or diagrams, etc., to get ideas about (and predict) the contents of a reading passage. to be expressed orally or in writing

A productive strategy-used when planning notetaking activities, procedures for answering questions, etc. 
Selective

attention

Self-

monitoring

Self-

evaluation
Deciding in advance to attend to specific aspects of input, often by scanning for key words, concepts, and/or linguistic markers

Checking one's comprehension during listening or reading, or checking the accuracy and/or appropriateness of one's oral or written production while it is taking place

Judging how well one has accomplished a learning activity after it has been completed
Receptive-listening (or reading) for key words and discourse markers that will assist in comprehending the material, taking notes, etc. May also assist in production (question-answering) when students identify and underline the most important words in written questions.

Receptive or productive-checking one's own understanding of the material while learning is going on, or checking the accuracy of one's work as it is being done.

Receptive or productive--similar to Self-monitoring, but performed after the completion of the task. Often a collaborative endeavor enlisting the support of peers or the teacher.

\section{Cognitive Strategies}

Strategies that can be applied directly to the tasks of understanding and learning

Resourcing

Grouping

Notetaking

Summarizing

Deduction/

induction

Imagery

Auditory representation
Using target-language reference materials such as dictionaries, encyclopedias, or textbooks

Classifying words, terminology, or concepts according to their attributes

Writing down key words and concepts in abbreviated verbal, graphic, or numerical form during a listening or reading activity

Making a mental or written summary of information gained through listening or reading

\section{Applying rules to understand or} produce the second language, or making up rules based on language analysis

Using visual images (either mental or physical) to understand and remember new information

Playing back in one's mind the sound of a word, phrase, or longer language sequence
Often accomplished by making use of resources such as library materials, newspapers, magazines, etc.

Increasing one's understanding of content material by grouping together sets of things having similar characteristics. When the groups are named (labeled) as well, this strategy is better called Classifying.

Often applied during dictation activities. Tends to go hand in hand with Organizational planning and Selective

attention, for example, writing a column of numbers and then listening for the answers to a predetermined series of questions, or writing information on a T-list.

Sometimes accompanies Grouping, because a summary may consist of information in a series of separate categories. Also, often follows Notetaking as an end result.

Actually two strategies in one. Used when wrestling with any problem of linguistic form (grammar, spelling, punctuation, etc.), either by applying rules already learned (Deduction) or by formulating one's own rules on the basis of available linguistic evidence (Induction).

Using pictures to increase understanding, or making diagrams (e.g., Venn diagrams), charts, or other graphic representations to make information easier to understand and remember. Often accompanies Grouping (categorizing information).

May be teacher-initiated. Used particularly in Notetaking, when students must keep words and phrases in short-term memory as they write them down. 


\begin{tabular}{|c|c|c|}
\hline Elaboration & $\begin{array}{l}\text { Relating new information to prior } \\
\text { knowledge, relating different parts } \\
\text { of new information to each other, } \\
\text { or making meaningful personal } \\
\text { associations to the new information }\end{array}$ & $\begin{array}{l}\text { As in CALLA, building on one's previous knowledge of a } \\
\text { subject through discussion, research, or other } \\
\text { knowledge-gathering activities. Also, may involve the } \\
\text { expansion of language-elaborating one's linguistic } \\
\text { expression of a topic or idea (abbreviations } \rightarrow \text { words } \rightarrow \\
\text { sentences } \rightarrow \text { paragraphs). }\end{array}$ \\
\hline Transfer & $\begin{array}{l}\text { Using previous linguistic } \\
\text { knowledge or prior skills to assist } \\
\text { comprehension or production }\end{array}$ & $\begin{array}{l}\text { Making use of previously acquired linguistic knowledge or } \\
\text { skill to assist in coping with a new and different learning } \\
\text { task. May also involve the use of content-based } \\
\text { nonlinguistic knowledge or skills (e.g., mathematical; } \\
\text { problem-solving) }\end{array}$ \\
\hline Inferencing & $\begin{array}{l}\text { Using information in an oral or } \\
\text { written text to guess meanings, } \\
\text { predict outcomes, or complete } \\
\text { missing parts }\end{array}$ & $\begin{array}{l}\text { In the Foresee Approach, Predicting means guessing what } \\
\text { will come next in a story or other reading passage. } \\
\text { Inferencing means guessing at answers-to questions, } \\
\text { when grouping or taking notes, etc. }\end{array}$ \\
\hline
\end{tabular}

\section{Social-Affective Strategies}

Strategies through which the learner somehow enlists the support or assistance of other people (e.g., peers, teachers) or establishes an emotional or attitudinal state of mind conducive to success

Questioning for clarification

Cooperation

Self-talk
Eliciting from a teacher or peer additional information, rephrasing, examples, or verification
Working together with peers to solve a problem, pool information, check a learning task, model a language activity, or get feedback from an oral presentation

Reducing anxiety by using mental techniques that make one feel competent to do the learning task
Basically, the strategy of actively seeking help from others (peers or teacher).

Many applications. Often used with Self-evaluation Usually teacher-initiated (pairs, small groups), when students pool information, check answers, etc.

Sometimes involves the mental (or even spoken) "rehearsal" of the steps that need to be performed to accomplish a particular task. 